\title{
Virological Studies in Chronic Bronchitis
}

\author{
MARGARET B. EADIE,* M.B., CH.B.; E. J. STOTT,* B.A.; N. R. GRIST,* M.B., CH.B., B.SC., F.R.C.P.ED., M.C.PATH.
}

Brit. med. F., 1966, 2, 671-673

Though there is not likely to be one single cause for the complex disease of chronic bronchitis, the hypothesis that viruses play an important part in the initiation or progression of this condition is at least tenable (Scottish Standing Medical Advisory Committee, 1963 ; Stuart-Harris, 1965) and the serious effect of influenza $A$ infections on chronic bronchitics is well established (Stuart-Harris et al., 1953, Stuart-Harris and Hanley, 1957). Of the reported attempts to demonstrate a viral cause for acute exacerbations of chronic bronchitis those of Jack and Gandevia (1960) and Hennessy (1962) gave negative results. Serological studies have suggested an association between exacerbations and infections with respiratory syncytial virus (Sommerville, 1963) and influenza B, and possibly with para-influenza viruses (Stark et al., 1965). Carilli et al. (1964), using both serological and isolation techniques, showed a high incidence of virus infections in exacerbations of chronic bronchitis. Infections with rhinoviruses were not detected in any of these studies. The present investigation was designed to seek evidence of virus infections by observing a group of patients with chronic bronchitis in their homes for several years and studying episodes of respiratory illness by serological and isolation techniques designed to detect infections with most of the known respiratory viruses.

\section{Materials and Methods}

\section{Clinical}

The investigation was carried out between January 1962 and June 1964. Fifteen patients with chronic bronchitis, as defined by Scadding (1959), were selected from the lists of three general practitioners on the basis of two main criteria: (a) that they would be likely to cooperate effectively, and (b) that there would be other persons, preferably children, in the family who would increase the likelihood of virus infections being introduced into the household.

- Department of Infectious Diseases, University of Glasgow, and Regional Virus Laboratory, Ruchill Hospital, Glasgow.
In order to confirm the diagnosis and to establish their initial condition, 14 of the 15 patients had an initial general examination in hospital which included chest $x$-ray film, Wright peak flow-meter reading, estimation of haemoglobin, white blood cell count, differential white blood cell count, measurement of sputum volume produced in the first hour of the day, and the collection of an initial specimen for virus serology. The fifteenth patient was unable to attend hospital, but had the complete general examination apart from a chest $x$-ray film. An augmented form of the standard short questionary (M.R.C., 1960) was also completed for each of the 15 patients on enrolment, and they were asked to notify one of us (M.B.E.), by postcard or telephone, of any acute respiratory illness of themselves or of their family contacts. Eight males and seven females aged from 29 to 76 years were accepted for the study. The duration of their bronchitis varied between 2 and 47 years, and they have been distributed according to the M.R.C. classification (M.R.C., 1965) and questionary (M.R.C., 1960), as shown in Tables I and II. There were 41 family contacts, 16 under 10 years of age.

The bronchitics were visited in their own homes every fortnight or more often when they gave notice of an acute respiratory illness in the household. Each respiratory episode

TABLB II.-Characteristics of 15 Bronchitics (M.R.C., 1960)

\begin{tabular}{|c|c|c|c|c|c|}
\hline & & & & Male & Female \\
\hline Age $\begin{cases}25-44 & \text { years } \\
45-64 & \text { " } \\
65-84 & \text { " }\end{cases}$ & $\begin{array}{ll}\because & \\
\because & \end{array}$ & $\begin{array}{l}\cdots \\
\cdots\end{array}$ & $\because$ & $\begin{array}{l}3 \\
5 \\
0\end{array}$ & $\begin{array}{l}2 \\
4 \\
1\end{array}$ \\
\hline Phlegm production & $\left\{\begin{array}{c}\text { Grade } \frac{1}{2} \\
川\end{array}\right.$ & $\ldots$ & $\because$ & $\begin{array}{l}3 \\
5\end{array}$ & $\begin{array}{l}3 \\
4\end{array}$ \\
\hline Sputum volume & {$\left[\begin{array}{cc}\text { Group } & 0 \\
\Rightarrow & 1 \\
\Rightarrow & 2 \\
\Rightarrow & 3 \\
\Rightarrow & 4\end{array}\right.$} & $\begin{array}{l}\ldots \\
\ddot{0} \\
\ddot{y}\end{array}$ & 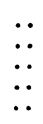 & $\begin{array}{l}1 \\
1 \\
1 \\
4 \\
1\end{array}$ & $\begin{array}{l}2 \\
0 \\
3 \\
1 \\
1\end{array}$ \\
\hline Smoking habits & $\left\{\begin{array}{cc}\text { Group } & 0 \\
\# & 1 \\
\# & 2 \mathrm{~L} \\
\Rightarrow & 2 \mathrm{M} \\
\Rightarrow & 2 \mathrm{H}\end{array}\right.$ & $\begin{array}{l}\ldots \\
\because \\
\cdots\end{array}$ & $\begin{array}{l}. . \\
\because \\
\cdots\end{array}$ & $\begin{array}{l}1 \\
1 \\
3 \\
2 \\
1\end{array}$ & $\begin{array}{l}1 \\
2 \\
3 \\
1 \\
0\end{array}$ \\
\hline
\end{tabular}

TABLE I.-Characteristics of 15 Bronchitics

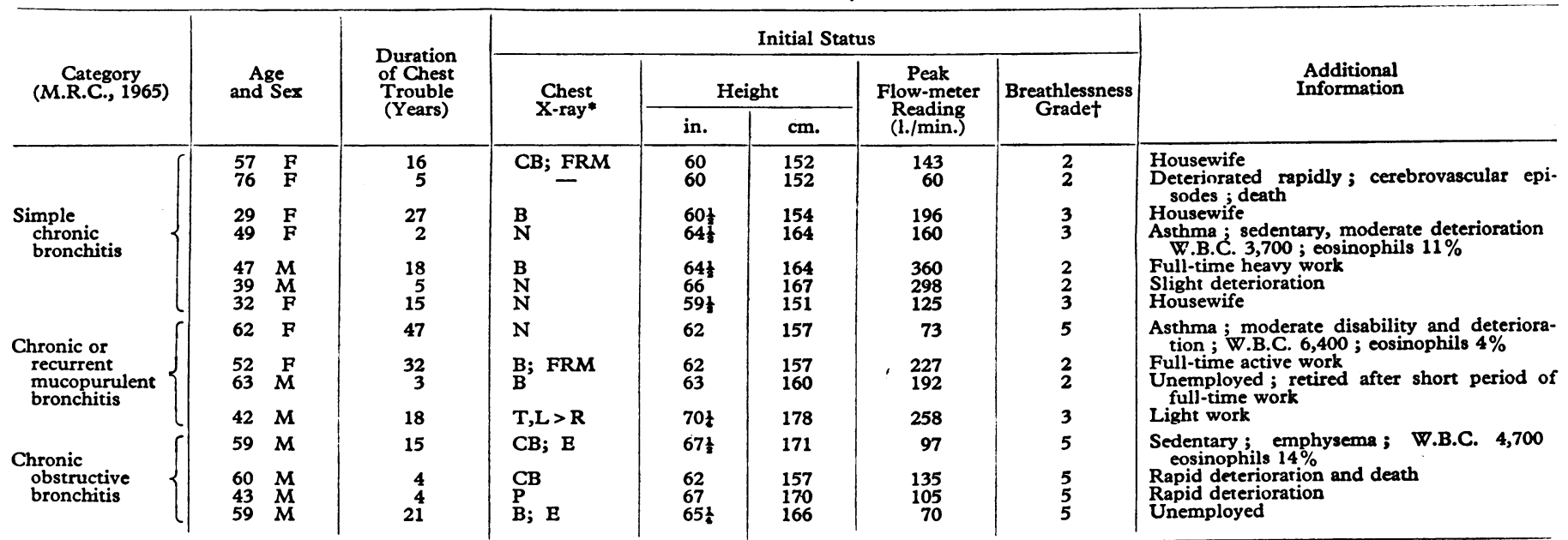


was investigated virologically by the collection of a nasal washing, throat swab, and, where possible, sputum. Blood sera were collected at initial enrolment, in pairs related to episodes of illness during the first one and a half years, and at the beginning (October) and end (April) of the 1963-4 winter.

\section{Virological}

Specimens were usually brought back to the laboratory for examination within two hours of collection, but occasionally they were held overnight at $4^{\circ} \mathrm{C}$. The nasal washings and transport medium in which the throat swabs had been placed were centrifuged at $1,500 \mathrm{~g}$ for 10 minutes and the supernates inoculated into tissue cultures. Specimens of sputum were diluted $1 / 4$ with transport medium, shaken with glass beads, centrifuged at $1,500 \mathrm{~g}$ for 10 minutes, and the supernate inoculated into tissue cultures. All specimens were tested in the following three types of tissue culture: (a) secondary rhesus-monkey kidney rolled at $33^{\circ} \mathrm{C}$. in Parker's medium $199 ;(b)$ " Bristol" HeLa cells held stationary at $36^{\circ} \mathrm{C}$. in Eagle's minimum essential medium containing $2 \%$ inactivated rabbit serum and $0.18 \%$ sodium bicarbonate; and (c) a semicontinuous strain of human-embryo-kidney fibroblasts rolled at $33^{\circ} \mathrm{C}$. in Eagle's minimum essential medium containing $1 \%$ inactivated calf serum, $5 \%$ tryptose phosphate broth, and $0.04 \%$ sodium bicarbonate. Viruses which produced an enterovirus-like cytopathic effect in human-embryo-kidney fibroblasts under the above conditions and which were chloroform-stable and acid-labile were classified as rhinoviruses; those which produced a cytopathic effect in both monkey-kidney and humanembryo cells were called $M$ strains; and those which produced a cytopathic effect only in human cells were classified as $\mathrm{H}$ strains.

Paired blood sera were tested for antibodies to influenza A, $B$, and $C$, adenovirus group, and respiratory syncytial virus, by complement-fixation methods, as described by Grist et al. (1966).

\section{Meteorological}

Readings of temperature, visibility, and relative humidity taken four times daily were obtained from the Glasgow Weather Centre.

\section{Results}

Altogether 94 respiratory episodes were investigated-19 in family contacts and 75 in chronic bronchitics. Ten of the 15 bronchitics were observed for two and a half years, four for one and a half years, and one for one year. The average number of illnesses per bronchitic per year was 2.5 , ranging from 0 to 7.8 .

The classification and virological results of the 94 episodes investigated are shown in Table III, in which the illnesses were defined on clinical evidence obtained before any laboratory results were known, as follows:

Cold : Infection of the upper respiratory tract with predominating rhinitis and pharyngitis. These colds could be subdivided into (a) those which did not affect the chest or caused only slight increase in wheeze and cough and no incapacitation, and (b) those which were associated with an exacerbation of bronchitis.

Influenza-like illness: Generalized aches, fever, and headache with or without upper-respiratory-tract symptoms.

Exacerbation: Marked increase in dyspnoea, wheezing, and cough of at least 24 hours' duration. This group included cases of acute exacerbation, subacute exacerbation, and acute worsening of chronic deterioration. The latter subdivision included several older patients who showed an increase in signs or symptoms during a slow deterioration over the winter months, the time of "onset" being difficult to determine.

In summary, respiratory viruses considered relevant were isolated from 4 out of 19 episodes in family contacts, from 1 out of 26 exacerbations of chronic bronchitis without colds, from 11 out of 42 colds, and from 1 out of 7 influenza-like illnesses. Inclusion of three acceptable serological results (fourfold or greater titre rises) raised the proportion of identified virus infections to $16(21 \%)$ of 75 illnesses in bronchitics. The most frequently diagnosed infections were attributable to myxoviruses and rhinoviruses, the latter being isolated from 11 $(23 \%)$ of 47 illnesses affecting the chest but from only $1(4 \%)$ of 28 other illnesses. Two of the rhinoviruses were $M$ strains and the remainder $H$ strains. They were isolated from 7 of the 15 bronchitics: from three separate illnesses of one bronchitic, from two illnesses of three, and from single illnesses of

INFECTIONS
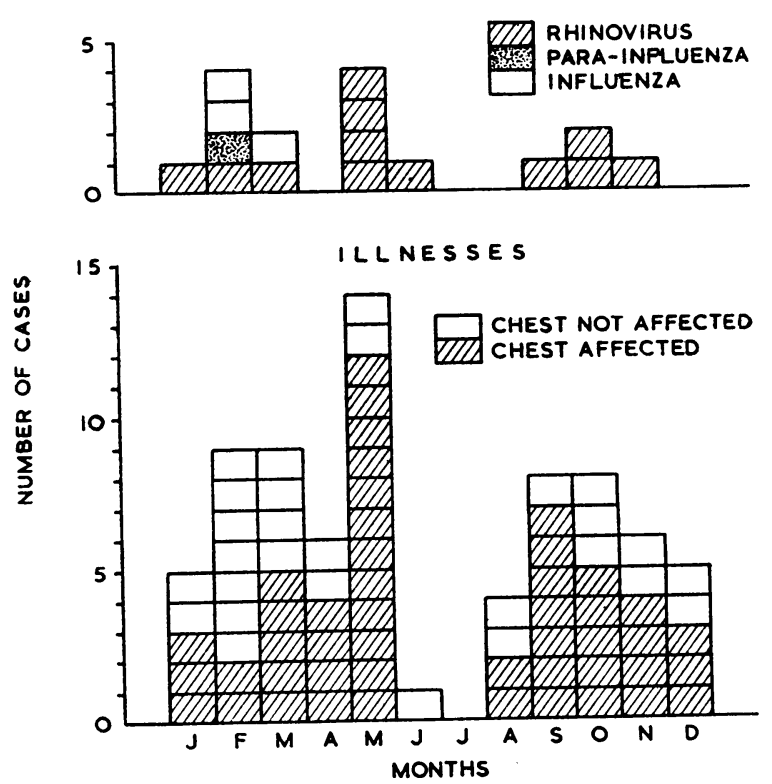

Monthly distribution of 16 virus infections and 75 episodes of respiratory illness found in 15 chronic bronchitics. Figures for January-June based on three years' observation, for July-December on two years' observations; figures for July unrepresentative because of local holidays.

TABLE III.-Clinical Classification and Virological Results of 94 Respiratory Episodes

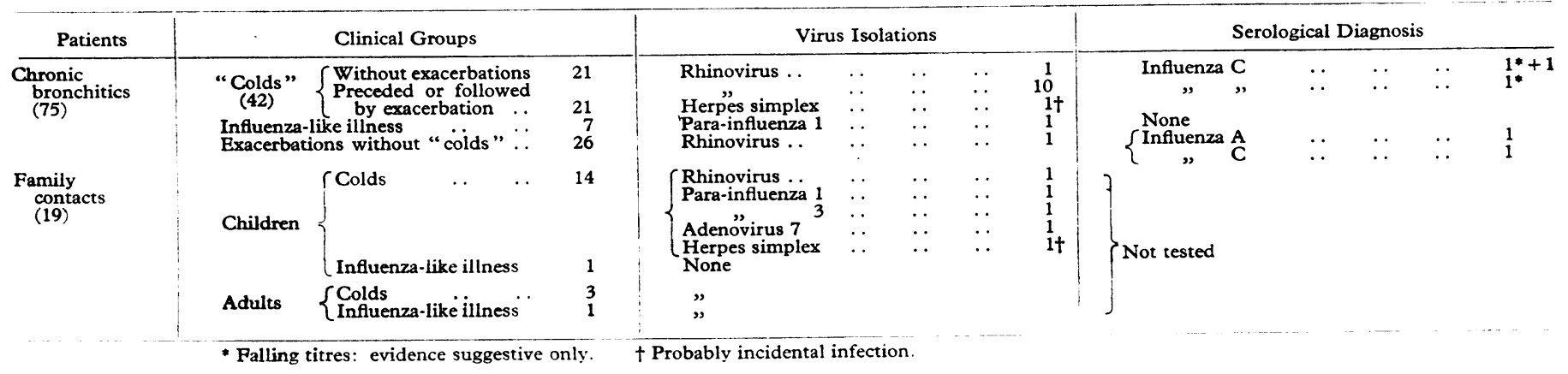


three patients. Comparison of the seven rhinovirus-positive bronchitics with the remaining eight showed that those from whom rhinoviruses were isolated tended to be younger, to have more family contacts under 10 years, and to have a lower M.R.C. phlegm-production grade. Rhinoviruses were isolated from sputum in five cases, in three of which a throat swab taken at the same time yielded no virus.

The seasonal distribution of the respiratory episodes and virus infections is shown in the Chart. Exacerbations of bronchitis and isolations of rhinoviruses were most common in the spring and autumn months, but no significant correlation was found between the incidence of respiratory episodes and any of the meteorological data recorded.

\section{Discussion}

Influenza viruses, para-influenza viruses, and respiratory syncytial virus have all been associated with exacerbations of chronic bronchitis. Our findings suggest that rhinoviruses may also play a part in this process.

Our results differ from those of Sommerville (1963) and Carilli et al. (1964) in that respiratory syncytial virus infections were not definitely associated with any exacerbations, though respiratory syncytial virus is known to have caused outbreaks of respiratory illness in children in Glasgow during both winters covered by this study (Ross et al., 1964 ; unpublished data).

Only Carilli et al. (1964) have previously reported the use of human-embryo-tissue cultures for attempted isolation of rhinoviruses from bronchitics. Their failure to isolate these viruses might partly be due to their failure to examine nasal washings. The selection of bronchitics with family contacts for our study may account for some of the differences between our findings and those of other workers, but comparison of the groups investigated is difficult, since they are poorly defined in other virological studies.

The isolation of rhinoviruses significantly more often $(P<0.01)$ from colds affecting the chest than from those not affecting the chest may simply indicate greater virus-shedding during exacerbations. However, the isolation of rhinoviruses from sputum, sometimes in the absence of detectable virus in the throat, our finding that the titre of rhinovirus in sputum may be as much as $10^{4} \mathrm{TCD}_{50} / \mathrm{ml}$. (unpublished observation), and the report by Cate et al. (1965) of the production of tracheobronchitis in volunteers inoculated with a rhinovirus, indicate that rhinoviruses can infect the lower respiratory tract of adults. The finding that $38 \%$ of the exacerbations in this survey were preceded by colds suggests that the relationship between rhinoviruses and exacerbations may sometimes be a causal one. Although we have no parallel external control group for these rhinovirus isolations, it may be noted that rhinoviruses were isolated in a variety of semicontinuous human embryo cultures from $40 \%$ of colds of a younger group of adults without bronchitis (mainly members of laboratory staff).

The notification of only 19 illnesses in family contacts suggests that only a small proportion of their respiratory episodes reached our notice. We have therefore not used family contacts as a control group.

The studies so far reported from this and other centres justify further investigation of the role of respiratory syncytial virus and rhinoviruses in chronic bronchitis. Future investigations might also explore the role of mycoplasmas and the possibility of unmasking latent agents from biopsy specimens.

\section{Summary}

Fifteen chronic bronchitics were visited regularly over two and a half years, and any respiratory illness of these patients or their family contacts was investigated virologically. During this period there were 75 illnesses in the bronchitics, of which $21 \%$ were associated with proved virus infection.

Rhinoviruses were isolated from $23 \%$ of illnesses which affected the chest but from only $4 \%$ of those which did not.

We are grateful to the 15 patients for their cooperation in this investigation, and to Drs. A. Clarke, W. Blair, and W. K. Brown for helping us to select and allowing us to study these patients from their practices. We thank Dr. C. A. C. Ross for the results of complement-fixation tests, and Mr. S. McMichael, Miss M. Friel, and Miss $M$. Walker for technical assistance. We also acknowledge a grant made by the Secretary of State for Scotland on the advice of the Advisory Committee for Medical Research.

\section{REFERENCES}

Carilli, A. D., Gohd, R. S., and Gordon, W. (1964). New Engl. F. Med., 270, 123 .

Cate, T. R., Couch, R. B., Fleet, W. F., Griffith, W. R., Gerone, P. J., and Knight, V. (1965). Amer.' F. Epidem., 81, 95.

Grist, N. R., Ross, C. A. C., Bell, E. J., and Stott, E. J. (1966). Diagnostic Methods in Clinical Virology. Blackwell, Oxford. In press. Hennessy, A. V. (1962). Amer. Rev. resp. Dis., 86, 350

Hennessy, A. V. (1962). Amer. Rev. resp. Dis.,

Jack, I., and Gandevia, B. (1960). Ibid., 82, 482. 1665.

(1965). Lancet, 1, 775.

Ross, C. A. C., Stott, E. J., McMichael, S., and Crowther, I. A. (1964), Arch. ges. Virusforsch., 14, 553.

Scadding, J. G. (1959). Lancet, 1, 323

Sommerville, R. G. (1963). Ibid., 2, 1247.

Standing Medical Advisory Committee, Scotrish Health Services Council (1963). Report of a Subcommittee. H.M.S.O. London.

Stark, J. E. Heath, R. B., and Curwen, M. P. (1965). Thorax, 20, 124 Stark, J. E., Heath, R. B., and Curwen, M. P. (1965).

Stuart-Harris, C. H. (1965). Scot. med. F., 10, 93 .

and Hanley, T. (1957). Chronic Bronchitis, Emphysema, and Cor
Pulmonale. Wright, Bristol.
Pownall, M., Scothorne, C. M., and Franks, Z. (1953). Quart. J. Med., 22, 121 . 